\title{
The Integral Plasmodium Life Cycle Phenomenon: Gametocyte Genes
}

\section{Vineeta Singh* and Amit Kumar}

National Institute of Malaria Research (ICMR), Sector-8, Dwarka, New Delhi 110077, India

\begin{abstract}
Gametocytes are the sexual stages of the Plasmodium species. The transmission of parasite relies on these gametocytes which are the crucial link in its life cycle. The biology of parasitic life cycle is complex with the invasion of host red blood cells (RBCs) by merozoites after the pre-erythrocytic invasion and followed with erythrocytic invasions and multiplications. This review examines the involvement of gametocyte-specific genes in gametocytogenesis. Here we look at the six gametocyte specific genes- Pfs16, Pfs25, Pfg27, Pfs48/45, Pfs230 and Pfg377; their developmental commitment, gene expression causing cellular and molecular changes in sexual differentiation. The in depth understanding of the gametocytogenesis in the transition from asexual to sexual differentiation could help to develop new strategies to curtail effectively the malaria transmission.
\end{abstract}

Keywords: Gametocyte genes; Gamete biology; Gametocytogenesis

\section{Introduction}

The World Health Organization(WHO) has estimated approximately 198 million cases and 5,84,000 annual deaths due to malaria worldwide [1]. The five species of Plasmodium that infect humans most commonly are $P$. falciparum, $P$. vivax, $P$. ovale, $P$. malariae and $P$. knowlesi with $P$. falciparum the most deadly among them [2]. The malarial parasite life cycle involves two hosts; a malaria-parasite infected female Anopheles mosquito and the human host. During the blood meal transmission from the vector to the vertebrate host is ensured by the sporozoites present in the saliva of the biting vector. In human host, the asexual life cycle begins where some parasites differentiate into sexual erythrocytic stages (gametocytes). The process of development of sexual stages from the asexual stages within the host is called gametocytogenesis. The sporogonic cycle continues in the mosquito when these gametocytes, male (microgametocytes) and female (macrogametocytes) are ingested by an Anopheles mosquito during the blood meal. In the mosquito's stomach, the microgametes fuse with the macrogametes forming zygotes and later develop into oocysts. The oocysts grow, rupture, and release sporozoites, which reach the mosquito's salivary glands so that whenever, the infected mosquito bites another human host, inoculation of the sporozoites into a new human host perpetuates the malaria life cycle [3]. Gametocytes are the sexual stages of the malaria parasites that develop in the human host and are transmitted to the definitive vector-mosquito to continue its life cycle. Although it is well known that gametocytes are responsible for malaria transmission, relatively little is known about the gamete biology and the molecular mechanisms involved in the process of gametocytogenesis. The gametocytogenesis is the transition phase in the life cycle of the parasite where it changes morphologically as well as biochemically from asexual to sexual stages which occur in the inner membrane complex (IMC) of the erythrocyte [4]. This sexual differentiation is dependent upon a coordinated cascade of gene expression, involving a number of 'sexual-stage-specific' genes and their protein products [5]. Gametocytes are the key targets in the life cycle of the malaria parasite and for eliminating malaria it is necessary that the control strategies aiming to eliminate gametocytes need to be devised.

\section{Gametocyte Development Morphology}

The gametocytes are the gamete precursor in the mosquito midgut to the gamete sporogamy. The growth and development of the $P$. falciparum gametocytes is divided into five (I-V) morphologically distinguishable stages spread over 8-17 days from merozoite invasion to mature gametocyte in the host RBCs [6]. Stage I gametocytes are very much similar to the young asexual trophozoite. The first morphological differentiations start appearing in stage IIb as a new subpellicular cytoskeleton starts to form supported by few microtubules; giving the gametocytes their characteristic elongated shape and pointed ends [5]. The distinguishable male and female forms start to show at stage III where one region of the parasite straightens and the characteristic $\mathrm{D}$-shape of the gametocytes starts to form [5,7]. The gametocytes become more symmetrical in stage IV as the subpellicular cytoskeleton formation is completed [4]. Sexual differentiation is accentuated in female gametocyte at IV stage with a marked increase in the density of ribosomes, endoplasmic reticulum, Golgi complex and mitochondria than in male gametocytes. This clearly indicates the subsequent development of the macro-gametocyte as the fertilized egg. Successful transformation of the stage IV parasite to the morphologically mature stage $\mathrm{V}$ gametocyte is accompanied by a collapse of the pointed spindle into a crescent shape where the host cell appears as a flattened thin layer around the parasite [5]. The morphological characteristics of gametocyte developmental stages are described in Table 1.

\section{Localization of Gametocytes}

The developing gametocytes are absent from the peripheral circulation, as they adhere to the endothelial erythrocytes of the host organs (heart, lung, liver, brain and tissues as skin) and thus are able to avoid the phagocytic clearance [8]. This is the major reason for practically nil gametocytes to be seen in the peripheral blood and it is only after the peak of asexual parasitaemia that the gametocytes can be seen in peripheral smears. The cytoadherence phenomenon in infected red blood cells (IRBCs), is mediated by a series of host receptors: most strongly with the glycoprotein CD36, intercellular adhesion molecule-1 (ICAM-1), vascular cell adhesion molecule- 1 (VCAM-1), P-selectin and

*Corresponding author: Vineeta Singh, Cell Biology Laboratory and Malaria Parasite Bank, National Institute of Malaria Research (ICMR), Sector-8, Dwarka, New Delhi 110077, India, Tel: 011-2530714; E-mail: vineetas_2000@yahoo.com

Received February 13, 2015; Accepted April 21, 2015; Published April 27, 2015

Citation: Vineeta Singh, Amit Kumar (2015) The Integral Plasmodium Life Cycle Phenomenon: Gametocyte Genes. J Bacteriol Parasitol 6: 224 doi: 10.4172/2155 9597.1000224

Copyright: (C) 2015 Vineeta Singh, et al. This is an open-access article distributed under the terms of the Creative Commons Attribution License, which permits unrestricted use, distribution, and reproduction in any medium, provided the original author and source are credited. 
Citation: Vineeta Singh, Amit Kumar (2015) The Integral Plasmodium Life Cycle Phenomenon: Gametocyte Genes. J Bacteriol Parasitol 6: 224. doi: 10.4172/2155-9597.1000224

Page 2 of 5

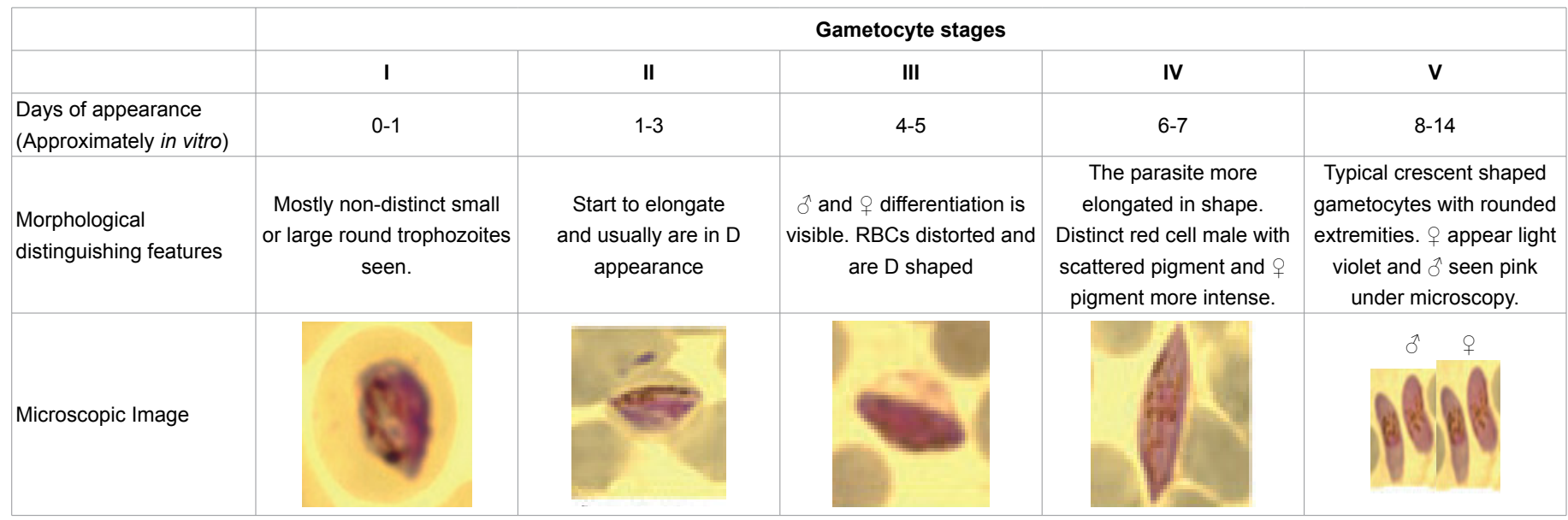

Table 1: Morphological characteristic of the gametocytes.

\begin{tabular}{|c|c|c|c|c|c|c|}
\hline $\begin{array}{l}\text { Sexual } \\
\text { gametocytes } \\
\text { gene }\end{array}$ & Gene ID and Source & $\begin{array}{l}\text { Location on } \\
\text { chromosome }\end{array}$ & $\begin{array}{l}\text { Size of } \\
\text { coding } \\
\text { regions }(b p)\end{array}$ & Protein & $\begin{array}{l}\text { Initiation of gene } \\
\text { expression }\end{array}$ & Function \\
\hline Pfs 16 & $\begin{array}{l}\text { PF3D7_0406200 } \\
\text { PlasmoDB }\end{array}$ & 4 & $473 \mathrm{bp}$ & Sexual stage protein & $\begin{array}{l}\text { Subpopulation of schizonts, } \\
\text { early rings and stage I }\end{array}$ & Not well known [19] \\
\hline Pfs 25 & $\begin{array}{l}\text { PF3D7_1031000 } \\
\text { PlasmoDB }\end{array}$ & 10 & $674 \mathrm{bp}$ & $\begin{array}{l}25 \mathrm{KDa} \text { ookinete } \\
\text { surface antigen } \\
\text { precursor }\end{array}$ & Ookinete membrane & $\begin{array}{l}\text { Start the formation of oocyst and a good } \\
\text { target antigen for transmission blocking } \\
\text { vaccine [33] }\end{array}$ \\
\hline $\operatorname{Pfg} 27$ & $\begin{array}{l}\text { PF3D7_1302100 } \\
\text { PlasmoDB }\end{array}$ & 13 & $654 \mathrm{bp}$ & $\begin{array}{l}\text { Gamete antigen } \\
27 / 25\end{array}$ & Gametocyte cytoplasm & $\begin{array}{c}\text { Maturation of gametocyte and } \\
\text { confirmation of RNA binding }[7,12]\end{array}$ \\
\hline Pfs230 & $\begin{array}{l}\text { PF3D7_0209000 } \\
\text { PlasmoDB }\end{array}$ & 2 & $9408 \mathrm{bp}$ & 6-cysteine protein & Stage II gametocytes & $\begin{array}{l}\text { The protein help in adherence of gametes } \\
\text { to RBCs }[42,46]\end{array}$ \\
\hline$P f s 48 / 45$ & $\begin{array}{c}\text { PF13_0247 } \\
\text { NCBI }\end{array}$ & 13 & $1347 \mathrm{bp}$ & $\begin{array}{l}\text { Transmission } \\
\text { blocking target } \\
\text { antigen precursor }\end{array}$ & Gametocyte membrane & $\begin{array}{l}\text { Female macrogametes attach to } \\
\text { microgametes with the help of fertile male } \\
\text { gametes }[22,50]\end{array}$ \\
\hline Pfg377 & $\begin{array}{l}\text { PF3D7_1250100 } \\
\text { PlasmoDB }\end{array}$ & 12 & $9360 b p$ & $\begin{array}{l}\text { Osmiophilic bodies } \\
\text { protein }\end{array}$ & $\begin{array}{l}\text { Osmiophilic bodies and } \\
\text { Stage III }\end{array}$ & $\begin{array}{l}\text { Formation of osmiophilic bodies, and } \\
\text { egression of female gametes [56] }\end{array}$ \\
\hline
\end{tabular}

Table 2: Details of gametocyte specific genes.

thrombospondin (TSP) [9-11]. The parasite ligand for CD36, ICAM-1 and TSP has been identified as the $P$. falciparum erythrocyte membrane protein 1 (PfEMP-1) [12]. The parasite ligands associated with stage II and IV gametocyte sequestration in bone marrow include ICAM-1, CD49c, CD166 and CD164 receptors [13,14]. The ligand candidate or their marker could be targeted by immunotherapies that specifically bind or inhibit them. Some of the parasite target domains are listed here:

- PfEMP-1 - Present on the parasitized RBCs and form a key role in cytoadherence; the importance of this parasite ligand is well known [15].

- STEVOR - The subtelomeric variant open reading frame (stevor) genes code for the STEVOR proteins found on the surface of gametocyte III-IV stages have a major role in antigenic variation [16].

- RIFIN - Repetitive interspersed family (RIFIN) gene family play a crucial role in antigenic variation and developmental stages of parasites. The rif gene PF13_0006 of this family is most prominently expressed on stage $\mathrm{V}$ gametocytes and another rif gene PFI0025c is present in stage II and III gametocytes [17].

Host receptors on parasite ligands serve as potential vaccine targets for promising transmission- blocking vaccines [18].

\section{Gene Expression in Gametocytes}

In malaria life cycle gametocytes are the only stage which mediates transmission from the human host to the vector (Anopheles). The start of gametocyte production in the host bloodstream represents a transition period inducing several morphological and biochemical changes. The morphological changes in the gametocyte are accompanied by distinct patterns of sexual stage-specific gene expression [19]. The genes which are majorly involved in the process of gametocytogenesis are viz. $P f s 16$, $P f s 25, P f g 27, P f s 48 / 45, P f s 230$ and $P f g 377$ (Table 2). The differential expression of these specific genes help in the intra-erythrocytic development of the parasite and the specific promoter regions in these stage specific genes are essential for the transcriptional activity of these genes [20]. Most of these studies have concentrated on surface antigens, the majority of these characterized antigens are gamete antigens that are synthesized during gametocytogenesis $[7,19]$. The synthesis of $P f_{s} 16$ protein, one of the earliest to appear is found in parasitophorous vacuole membrane (PVM) of the young gametocytes marking the onset of gametocyte synthesis [20]. In the gametocyte formation $P f g 27 / 25$ is expressed approximately 30 hours after erythrocytic invasion [21]. The presence of $P f s 230$ and tubulin protein are pre-required for gamete formation and these are most likely the fertilization receptors, where $P f_{s} 48 / 45$ though present on both male and female gametes are only essential to male fertility [22]. Several proteins are required for sexual development and most notable proteins found in the mature female gametocyte are $P f_{s} 230$ and $P f_{s} 48 / 45$. The emergence of gametes from the red cell is mediated by osmiophilic bodies containing Pfg377 responsible for disruption of the enveloping RBCs [23]. The signalling processes regulating the formation of microgametes are triggered by 
the temperature fall (about $5^{\circ} \mathrm{C}$ ) along with the increased presence of the xanthurenic acid in mosquito [24,25]. The molecular events of the gametocytogenesis are not fully understood yet and it is believed that more genomic and proteomic studies will unravel the molecular processes involved in this phenomenon. The sexual stage specific genes serve as good targets for gene disruption studies as they are responsible for malaria transmission.

\section{Genetics of Gametocyte Genes}

The gametocytogenesis is a regulated process marked by distinct morphological and coordinated expression of sexual stage genes. This sexual differentiation process involves the development of gametocytes within the host RBCs from indistinguishable trophozoites (Stage I) to highly specialized, infective mature gametocytes (Stage V).

\section{Pfs16}

The occurrence of $P f s 16$ in gamete preparations primarily is due to the PVM that are still attached to the female gametes. The strains which produce mature gametocytes have high level of $P f_{s} 16$ at the earliest stage though its role during gametocyte maturation is not well known [26]. The expression of the $P f s 16$ gene in the sexual committed parasite is one of the earliest events in the sexual differentiation process and represents one of the earliest known markers of an individual parasite's commitment to gametocytogenesis [27]. The promoter activity of $P f_{s} 16$ can be detected as early as 24 hours after the erythrocyte invasion indicating that $P f_{s} 16$ is present during entire gametocyte maturation from stages I-V [27]. The early appearance of this gene in abundance is indicative that $P f_{s} 16$ have a major role to play in the formation of gametocytes. Some studies showed that though no morphological changes were seen in gametocytes but in male mutants exflagellation was not seen and were found to produce non-infective mosquitoes clearly indicating that importance of $P f s 16$ for optimal mature gametocyte production [28]. $P f_{s} 16$ is indispensable for male gametocyte ex-flagellation and produces a decisive signalling pathway for the gametocyte maturation process. It has been reported that $P f s 16$ is not essential for sexual development, but may have a role to play in optimal production of sexual parasites [29]. The $P f_{s} 16$ gene is upregulated at the onset of the sexual differentiation and the protein produced is localised in PVM and in all derived membranous structures [30]. The correlation between $P f_{s} 16 \mathrm{cDNA}$ in the first 40 hours of culture and the production of mature gametocytes is also seen hence, indicating $P f_{s} 16$ as an early marker of the developing gametocytes and can serve as a potential target of new anti-malarial drugs [31].

\section{Pfs 25}

Pfs 25 is an early expressed sexual stage protein found on the surface of $P$. falciparum zygotes and ookinetes [32]. It is a cysteine-rich $25-\mathrm{kDa}$ antigen composed of four tandem epidermal growth factor (EGF)like domains putatively anchored to the parasite's surface through a glycosylphosphatidylinositol (GPI) moiety and mainly expressed after the gametocyte have been transmitted to the mosquito gut $[33,34]$. Several studies have demonstrated that promoter region $(-722$ to -308$)$ of $P f s 25$ is very important for the expression of the gene [34]. The $P f_{s} 25$ gene used as a marker for female gametocytes, is located in the intracellular vesicles in gametocyte IV and V stages and its presence can be assessed in both non-activated and activated gametocytes [35]. Major part of the $P f s 25$ coding regions is conserved and recombinant vaccines based on this gene are currently underway which may assist in the control of lethal forms of human malaria [36]. Some studies suggest there is limited sequence polymorphism in $P f s 25$ and the antibodies against it showed relatively transmission blocking activity against field isolates [37].

\section{Pfg27}

$P f g 27$ is the sexual stage specific phosphoprotein present from the onset of sexual differentiation and is found throughout gametocyte maturation [38,39]. It was demonstrated that Pfg27 defective gametocytes show, distinct abnormalities in intra and extra-cellular membranous compartments, such as accumulation of parasitophorous vacuole-derived vesicle in the erythrocyte cytoplasm, large intracellular vacuole and discontinuities in their trilaminar cell membrane [40]. The antibody recognizes a 15 amino-acid region in the recombinant $P f g 27$ and also cross-reacts with the reduced and denatured forms of $P f s 230$ and $P f s 48 / 45$, in immunoprecipitation [41]. The protein is essential for the sexual development and maintaining the sexual phenotype of the parasite and its absence results in vacuolated highly disarranged and disintegrating parasites [42]

\section{Pfs230}

Another major protein associated with the gamete differentiation is $P f_{s} 230$, a $360 \mathrm{kDa}$ member of $P$. falciparum protein family. The $P f_{s} 230$ gene is the largest of the 10-member protein family found in $P$. falciparum with seven double cysteine rich domains present on the gamete surface and has a repeated pattern of associated amino acid motifs [43]. Pfs 230 is involved in protection of the parasite from the contents of the blood meal, in fertilization, or in the formation of exflagellation centers [44]. When gametogenesis is stimulated by incubating mature gametocytes in human serum at $25^{\circ} \mathrm{C}$, Pfs 230 undergoes proteolytic lysis from a $360 \mathrm{kDa}$ precursor to a doublet referred to as the $310 \mathrm{kDa}$ to mainly associate with the surface of the newly formed gamete [45]. Using peptide specific antibodies, the amino termini of the 307 and $300 \mathrm{kDa}$ forms have been mapped to between 477-487 and 523-555 amino acid, respectively, which is the region between the glutamate rich repeats and the cysteine motif domains [46]. These studies reveal that $P f_{s} 230$ is the surface molecule on males that mediates RBC binding and plays an important role in oocyst development, a critical step in malaria transmission [47]. It has been observed that $P f s 230$-minus males, in the presence or absence of $P f_{s} 48 / 45$, are unable to undergo exflagellation; also oocyst production and mosquito infectivity is significantly reduced, about $96-92 \%$ and $76-71 \%$ respectively [48]. It was found that only the processed forms exposed on the surface of the gamete are the targets of antibodies that block parasite transmission to the mosquito [49]. This mainly confirms the potential of $P f_{s} 230$ as a prime target for malaria transmission blocking reagents and contributes to the understanding of the molecular mechanisms involved in early stages of P. falciparum development in the mosquito midgut.

\section{Pfs $48 / 45$}

$P f_{s} 48 / 45$ is specifically expressed on the surface of the macrogametes of the malaria parasites and is a well-established transmission-blocking (TB) vaccine candidate [50,51]. Pfs48/45 consists of 1.5 double domains belonging to a family of proteins that are characterized by six positionally conserved cysteines (6-Cys proteins) having a signal peptide with putative GPI anchor sequence to locate on the parasite surface $[52,53,22]$. This sexual stage-specific $P f_{s} 48 / 45$ plays a central role in male fertility and assists in male micro-gametes attachment to fertile female macrogametes [50]. The presence of this gene is proven in sexual stages but is also present in asexual stages though in very small percentages [54]. The $P f s 48 / 45$ which is a target for developing transmission-blocking vaccine proves difficult for vaccine construction 
because of the conformational nature of its epitopes as shown by the panel of monoclonal antibodies (mAbs) developed from murine and rat could recognize only five different epitopes [50].

\section{Pfg 377}

The stage IV gametocytes show the presence of osmiophilic bodies, electron dense organelles observed in ultrastructural studies, located preferentially beneath the surface of female gametocytes [55]. The mature stage $\mathrm{V}$ macrogametes emerge only in the mosquito midgut from the RBC and their emergence is facilitated by the presence of osmophilic bodies in gametocytes. The protein which is associated with osmophilic bodies is encoded by Pfg377 gene [56]. The Pfg377 gene located on chromosome 12 is single exon of $9360 \mathrm{bp}$ and a novel sexual stage antigen of $\mathrm{P}$. falciparum. It is highly hydrophilic, $377 \mathrm{kDa}$ protein and homologous of which is found in human, rodent, avian and primate species. Pfg377 shows a characteristic granular appearance due to the shape and the cellular location of the osmophilic bodies. It contains four regions characterized by the presence of repeated amino-acid motifs. Region 1 is a proline-rich region beginning at amino acid residue 99, region 2 is a glutamic acid-rich region at residue 757 , region 3 is a histidine-rich region at residue 866 , and region 4 is a histidine- and glutamine-rich region at residue 1900 [56]. Pfg377 contains repeated sequences of highly variable length among different parasite clones, thus indicating the presence of more than one parasite clone. Recently it has been shown that targeted disruption of $P f g 377$ gene results in reduced emergence efficiency of gametocytes from the erythrocyte and the $P f g 377$ negative gametocytes also resulted in no infections completely [57].

\section{Discussion}

Malaria caused by the protozoan Plasmodium parasite comprises of a complex life cycle having infective stages; (pre-erythrocytic and erythrocytic phases) and a sexual phase known as gametocytogenesis (gametogenesis and sporogony stages). In this review article we have attempted to re-assess the knowledge regarding the gametocyte specific gene expression during the various stage developments. Malaria infections in symptomatic and asymptomatic episodes are most frequent in the transmission season, usually when mosquitoes are most abundant. The role gametocytes play in transmission of the diseases is highly pronounced but the molecular processes which are totally responsible for the process are still not fully known.

The dynamics of gametocytes are understood better extensively for symptomatic malaria cases, where waves of asexual parasitemia and fever are accompanied followed by increases in gametocyte prevalence $[58,59]$. The Plasmodium parasites know exactly at which point in their complex life cycle a particular gene expression is needed. Gametocytespecific proteins highly represented in gametocyte proteome are surface proteins which include; gamete antigen $P f g 27$ protein, $P f g 377$ protein, sexual stage specific protein $P f_{s} 16$ and transmission- blocking antigen proteins: $P f s 48 / 45$ and $P f s 230$ [60]. $P f s 48 / 45$ and $P f s 230$ are located as a complex on the plasma membrane of the gametocyte with only $P f_{s} 48 / 45$ being directly anchored to the membrane by a GPI moiety.

The gametocyte gene expression profiling approaches need to be coupled with more detailed knowledge of the underlying epidemiology dynamics of gametocyte carriage and infectivity. The success of malaria control and elimination is dependent on our understanding of gametocytes which in turn will result in a huge step in the right direction for developing the transmission blocking vaccine.

\section{Acknowledgments}

The authors would like to express gratitude to Director, NIMR for constant encouragement to research. They also acknowledge the support of all the staff members of the Parasite Bank in NIMR.

\section{References}

1. World Health Organization (2014) World Malaria Report, Geneva

2. Singh B, Kim Sung L, Matusop A, Radhakrishnan A, Shamsul SS, et al. (2004) A large focus of naturally acquired Plasmodium knowlesi infections in human beings. Lancet 363: 1017-1024.

3. Alano P (2007) Plasmodium falciparum gametocytes: still many secrets of a hidden life. Mol Microbiol 66: 291-302.

4. Dixon MW, Dearnley MK, Hanssen E, Gilberger T, Tilley L (2012) Shapeshifting gametocytes: how and why does P. falciparum go banana-shaped? Trends Parasitol 28: 471-478.

5. Lobo CA, Kumar N (1998) Sexual differentiation and development in the malaria parasite. Parasitol Today 14: 146-150.

6. Hawking F, Wilson ME, Gammage K (1971) Evidence for cyclic development and short-lived maturity in the gametocytes of Plasmodium falciparum. Trans $\mathrm{R}$ Soc Trop Med Hyg 65: 549-559.

7. Talman AM, Domarle O, McKenzie FE, Ariey F, Robert V (2004) Gametocytogenesis: the puberty of Plasmodium falciparum. Malar J 3: 24

8. Howard RJ (1988) Malarial proteins at the membrane of Plasmodium falciparum-infected erythrocytes and their involvement in cytoadherence to endothelial cells. Prog Allergy 41: 98-147.

9. Barnwell JW, Asch AS, Nachman RL, Yamaya M, Aikawa M, et al. (1989) A human 88-kD membrane glycoprotein (CD36) functions in vitro as a receptor for a cytoadherence ligand on Plasmodium falciparum-infected erythrocytes. J Clin Invest 84: 765-772.

10. Ockenhouse CF, Tegoshi T, Maeno Y, Benjamin C, Ho M, et al. (1992) Human vascular endothelial cell adhesion receptors for Plasmodium falciparuminfected erythrocytes: roles for endothelial leukocyte adhesion molecule 1 and vascular cell adhesion molecule 1. J Exp Med 176: 1183-1189.

11. Sherman IW, Eda S, Winograd E (2003) Cytoadherence and sequestration in Plasmodium falciparum: defining the ties that bind. Microbes Infect 5: 897-909.

12. Baruch DI, Gormely JA, Ma C, Howard RJ, Pasloske BL (1996) Plasmodium falciparum erythrocyte membrane protein 1 is a parasitized erythrocyte receptor for adherence to CD36, thrombospondin, and intercellular adhesion molecule 1. Proc Natl Acad Sci USA 93: 3497-3502.

13. Warimwe GM, Keane TM, Fegan G, Musyoki JN, Newton CR, et al. (2009) Plasmodium falciparum var gene expression is modified by host immunity. Proc Natl Acad Sci U S A 106: 21801-21806.

14. Rogers NJ, Hall BS, Obiero J, Targett GAT, Sutherland CJ (2000) A model for sequestration of the transmission stages of Plasmodium falciparum: adhesion of gametocyte-infected erythrocytes to human bone marrow cells. Infect Immun 68: 3455-3462.

15. Udomsangpetch R, Pipitaporn B, Silamut K, Pinches R, Kyes S, et al. (2002) Febrile temperatures induce cytoadherence of ring-stage Plasmodium falciparum-infected erythrocytes. Proc Natl Acad Sci U S A 99: 11825-11829.

16. Niang M, Yan Yam X, Preiser PR (2009) The Plasmodium falciparum STEVOR multigene family mediates antigenic variation of the infected erythrocyte. PLoS Pathog 5: e1000307.

17. Wang CW, Mwakalinga SB, Sutherland CJ, Schwank S, Sharp S, et al. (2010) Identification of a major rif transcript common to gametocytes and sporozoites of Plasmodium falciparum. Malar J 9: 147

18. Ramirez JL, Garver LS, Dimopoulos G (2009) Challenges and approaches for mosquito targeted malaria control. Curr Mol Med 9: 116-130.

19. Baker DA (2010) Malaria gametocytogenesis. Mol Biochem Parasitol 172: 57 65.

20. Sims JS, Militello KT, Sims PA, Patel VP, Kasper JM, et al. (2009) Patterns of gene-specific and total transcriptional activity during the Plasmodium falciparum intraerythrocytic developmental cycle. Eukaryot Cell 8: 327-38.

21. Sharma A, Sharma I, Kogkasuriyachai D, Kumar N (2003) Structure of 
a gametocyte protein essential for sexual development in Plasmodium falciparum. Nat Struct Biol 10: 197-203.

22. van Dijk MR, van Schaijk BC, Khan SM, van Dooren MW, Ramesar J, et al (2010) Three members of the 6-cys protein family of Plasmodium play a role in gamete fertility. PLoS Pathog 6: e1000853.

23. Suaréz-Cortés $P$, Silvestrini F, Alano $P$ (2014) A fast, non-invasive, quantitative staining protocol provides insights in Plasmodium falciparum gamete egress and in the role of osmiophilic bodies. Malar J 13: 389 .

24. Kuehn A, Pradel G (2010) The coming-out of malaria gametocytes. J Biomed Biotechnol 2010: 976827.

25. Tewari R, Straschil U, Bateman A, Böhme U, Cherevach I, et al. (2010) The systematic functional analysis of Plasmodium protein kinases identifies essential regulators of mosquito transmission. Cell Host Microbe 8: 377-387.

26. Moelans II, Klaassen CH, Kaslow DC, Konings RN, Schoenmakers JG (1991) Minimal variation in Pfs16, a novel protein located in the membrane of gametes and sporozoites of Plasmodium falciparum. Mol Biochem Parasitol 46: 311 313.

27. Dechering KJ, Thompson J, Dodemont HJ, Eling W, Konings RN (1997) Developmentally regulated expression of pfs16, a marker for sexual differentiation of the human malaria parasite Plasmodium falciparum. Mo Biochem Parasitol 89: 235-244.

28. Bousema T, Drakeley C (2011) Epidemiology and infectivity of Plasmodium falciparum and Plasmodium vivax gametocytes in relation to malaria contro and elimination. Clin Microbiol Rev 24: 377-410.

29. Kongkasuriyachai D, Fujioka H, Kumar N (2004) Functional analysis of Plasmodium falciparum parasitophorous vacuole membrane protein (Pfs16) during gametocytogenesis and gametogenesis by targeted gene disruption. Mol Biochem Parasitol 133: 275-285.

30. Bruce MC, Carter RN, Nakamura K, Aikawa M, Carter R (1994) Cellular location and temporal expression of the Plasmodium falciparum sexual stage antigen Pfs16. Mol Biochem Parasitol 65: 11-22.

31. Berry A, Deymier C, Sertorio M, Witkowski B, Benoit-Vical F (2009) Pfs 16 pivotal role in Plasmodium falciparum gametocytogenesis: a potential antiplasmodial drug target. Exp Parasitol 121: 189-192.

32. Kumar R, Angov E, Kumar N (2014) Potent Malaria Transmission-Blocking Antibody Responses Elicited by Plasmodium falciparum Pfs25 Expressed in Escherichia coli after Successful Protein Refolding. Infect Immun 82: 14531459.

33. Raj DK, Mishra S, Das BR, Dash AP (2005) Plasmodium falciparum Pfs25 gene promoter has no polymorphism in natural isolates of eastern India. Acta Protozool 44: 289-292.

34. Dechering KJ, Kaan AM, Mbacham W, Wirth DF, Eling W, et al. (1999) Isolation and functional characterization of two distinct sexual-stage-specific promoters of the human malaria parasite Plasmodium falciparum. Mol Cell Bio 19: $967-$

35. Ngwa CJ, Scheuermayer M, Mair GR, Kern S, Brügl T, et al. (2013) Changes in the transcriptome of the malaria parasite Plasmodium falciparum during the initial phase of transmission from the human to the mosquito. BMC Genomics 14: 256 .

36. Zou L, Miles AP, Wang J, Stowers AW (2003) Expression of malaria transmission-blocking vaccine antigen Pfs 25 in Pichia pastoris for use in human clinical trials. Vaccine 21: 1650-1657.

37. Smalley ME, Abdalla S, Brown J (1981) The distribution of Plasmodium falciparum in the peripheral blood and bone marrow of Gambian children. Trans R Soc Trop Med Hyg 75: 103-105.

38. Alano P, Premawansa S, Bruce MC, Carter R (1991) A stage specific gene expressed at the onset of gametocytogenesis in Plasmodium falciparum. Mol Biochem Parasitol 46: 81-88.

39. Lobo CA, Konings RN, Kumar N (1994) Expression of early gametocyte-stage antigens Pfg27 and Pfs16 in synchronized gametocytes and non-gametocyte producing clones of Plasmodium falciparum. Mol Biochem Parasitol 68: 151 154.

40. Olivieri A, Camarda G, Bertuccini L, van de Vegte-Bolmer M, Luty AJ, et al. (2009) The Plasmodium falciparum protein Pfg27 is dispensable for gametocyte and gamete production, but contributes to cell integrity during gametocytogenesis. Mol Microbiol 73: 180-193.
41. Ploton IN, Wizel B, Viscidi R, Kumar N (1995) Mapping of two overlapping linear epitopes in Pfg27 recognized by Plasmodium falciparum transmissionblocking monoclonal antibodies. Vaccine 13: 1161-1169.

42. Lobo CA, Fujioka H, Aikawa M, Kumar N (1999) Disruption of the Pfg27 locus by homologous recombination leads to loss of the sexual phenotype in $\mathrm{P}$. falciparum. Mol Cell 3: 793-798

43. Gerloff DL, Creasey A, Maslau S, Carter R (2005) Structural models for the protein family characterized by gamete surface protein Pfs230 of Plasmodium falciparum. Proc Natl Acad Sci U S A 102: 13598-13603.

44. Williamson KC (2003) Pfs230: from malaria transmission-blocking vaccine candidate toward function. Parasite Immunol 25: 351-359.

45. Williamson KC, Fujioka H, Aikawa M, Kaslow DC (1996) Stage-specific processing of Pfs 230 , a Plasmodium falciparum transmission-blocking vaccine candidate. Mol Biochem Parasitol 78: 161-169.

46. Brooks SR, Williamson KC (2000) Proteolysis of Plasmodium falciparum surface antigen, Pfs230, during gametogenesis. Mol Biochem Parasitol 106 $77-82$

47. Eksi S, Stump A, Fanning SL, Shenouda MI, Fujioka H, et al. (2002) Targeting and sequestration of truncated Pfs230 in an intraerythrocytic compartmen during Plasmodium falciparum gametocytogenesis. Mol Microbiol 44: 15071516

48. Eksi S, Czesny B, van Gemert GJ, Sauerwein RW, Eling W, et al. (2006) Malaria transmission-blocking antigen, Pfs230, mediates human red blood cell binding to exflagellating male parasites and oocyst production. Mol Microbio 61: 991-998.

49. Williamson KC, Keister DB, Muratova O, Kaslow DC (1995) Recombinant Pfs230, a Plasmodium falciparum gametocyte protein, induces antisera that reduce the infectivity of Plasmodium falciparum to mosquitoes. Mol Biochem Parasitol 75: 33-42.

50. van Dijk MR, Janse CJ, Thompson J, Waters AP, Braks JA, et al. (2001) A central role for P48/45 in malaria parasite male gamete fertility. Cell 104: 153164.

51. Carter R, Mendis KN, Miller LH, Molineaux L, Saul A (2000) Malaria transmission-blocking vaccines--how can their development be supported? Nat Med 6: 241-244

52. Stowers A, Carter R (2001) Current developments in malaria transmissionblocking vaccines. Expert Opin Biol Ther 1: 619-628.

53. Kaslow DC (2002) Transmission-blocking vaccines. Chem Immunol 80: $287-$ 307

54. Lasonder E, Ishihama Y, Andersen JS, Vermunt AM, Pain A, et al. (2002) Analysis of the Plasmodium falciparum proteome by high-accuracy mass spectrometry. Nature 419: 537-542.

55. Severini C, Silvestrini F, Sannella A, Barca S, Gradoni L, et al. (1999) The production of the osmiophilic body protein Pfg377 is associated with stage of maturation and sex in Plasmodium falciparum gametocytes. Mol Biochem Parasitol 100: 247-252.

56. Alano P, Read D, Bruce M, Aikawa M, Kaido T, et al. (1995) COS cell expression cloning of Pfg377, a Plasmodium falciparum gametocyte antigen associated with osmiophilic bodies. Mol Biochem Parasitol 74: 143-156.

57. de Koning-Ward TF, Olivieri A, Bertuccini L, Hood A, Silvestrini F, et al. (2008) The role of osmiophilic bodies and Pfg377 expression in female gametocyte emergence and mosquito infectivity in the human malaria parasite Plasmodium falciparum. Mol Microbiol 67: 278-290.

58. Dunyo S, Milligan P, Edwards T, Sutherland C, Targett G, et al. (2006) Gametocytaemia after drug treatment of asymptomatic Plasmodium falciparum. PLoS Clin Trials 1: e20

59. McKenzie FE, Jeffery GM, Collins WE (2007) Gametocytemia and fever in human malaria infections. J Parasitol 93: 627-633.

60. Florens L, Washburn MP, Raine JD, Anthony RM, Grainger M, et al. (2002) A proteomic view of the Plasmodium falciparum life cycle. Nature 419: 520-526. 